Review

\title{
Glycerol: A promising Green Solvent and Reducing Agent for Metal-Catalyzed Transfer Hydrogenation Reactions and Nanoparticles Formation
}

\author{
Alba E. Díaz-Álvarez ${ }^{\dagger}$ and Victorio Cadierno * \\ Laboratory of Organometallic Compounds and Catalysis (CSIC Associated Unit). \\ Department of Organic and Inorganic Chemistry, Institute of Organometallic Chemistry "Enrique \\ Moles", Faculty of Chemistry, University of Oviedo, E-33006 Oviedo, Spain; \\ E-Mail: aestrelladiaz@hotmail.com \\ $\dagger$ Present address: Department of Chemistry-BMC, Uppsala University, Box 576, \\ SE-75123 Uppsala, Sweden. \\ * Author to whom correspondence should be addressed; E-Mail: vcm@uniovi.es; \\ Tel.: +34-985-103-453; Fax: +34-985-103-446.
}

Received: 19 December 2012; in revised form: 15 January 2013 / Accepted: 21 January 2013 / Published: 23 January 2013

\begin{abstract}
Glycerol is a non-toxic, non-hazardous, non-volatile, biodegradable, and recyclable liquid that is generated as a byproduct in the manufacture of biodiesel fuel from vegetable oils. Due to its easy availability, along with its unique combination of physical and chemical properties, glycerol has recently emerged as an economically appealing and safe solvent for organic synthesis. Recent works have also demonstrated that glycerol can be used as a hydrogen source in metal-catalyzed transfer hydrogenation of organic compounds, such as aldehydes, ketones, olefins and nitroarenes. Herein, the advances reached in this emerging field are reviewed. The utility of glycerol as solvent and reducing agent for the generation of metal nanoparticles is also briefly discussed.
\end{abstract}

Keywords: glycerol; green solvent; hydrogen donor; transfer hydrogenation; reduction reactions; metal catalysis; metal nanoparticles 


\section{Introduction}

The impressive and fast development of the biodiesel industries has led to a large surplus of glycerol since about $100 \mathrm{~kg}$ of this byproduct are formed per ton of biodiesel (Scheme 1). According to recent estimates [1], world-wide production of glycerol could have reached 2 million tons in 2010 and it is expected to grow in the near future due to the increasing demand for biodiesel, as well as the emergence of other large-scale processes based on the conversion of cellulose and lignocelluloses in which glycerol is also a byproduct. Consequently, glycerol is nowadays in urgent requirement of exploitation [2]. Most efforts in this area are focusing on the development of procedures to convert glycerol into value-added chemicals, which have either been previously prepared from petrochemical sources or suffered from environmental problems during their preparation [1-12]. Glycerol reforming for hydrogen production [13-15] and its transformation into fuel additives [16] are also active areas of research.

Scheme 1. Overall reaction in the production of biodiesel.

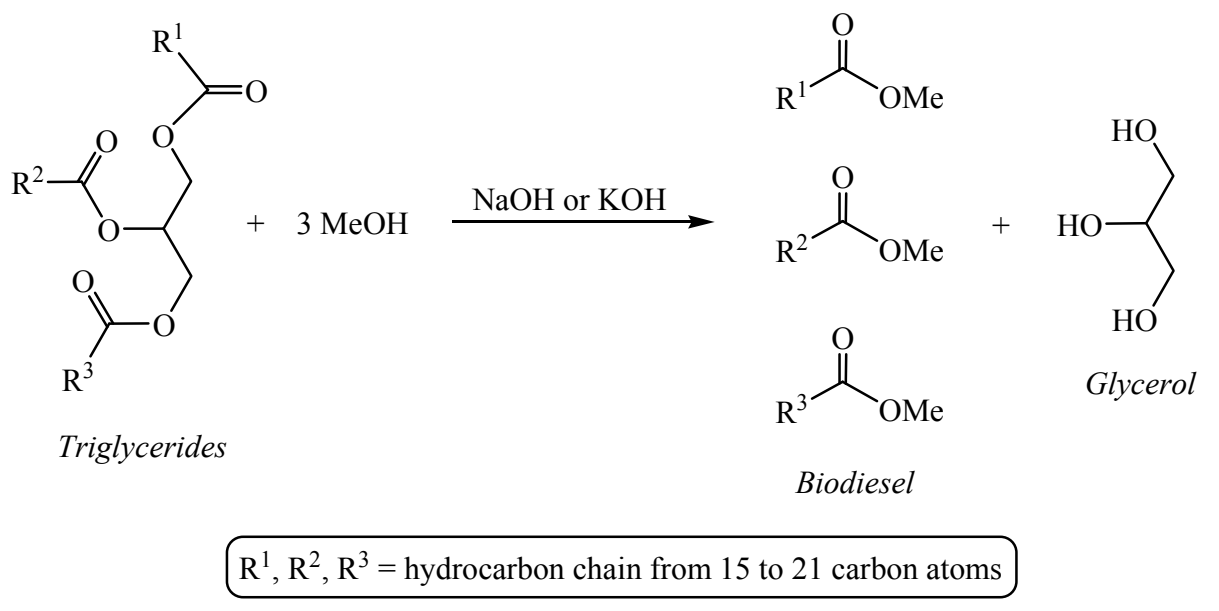

Replacing of hazardous chemicals by more environmentally friendly alternatives is also a matter of current interest, in line with the philosophy of Green Chemistry [17,18]. In this context, the introduction of ecofriendly solvents is a key area [19-22] because solvents account for $80 \%-90 \%$ of mass utilization in a typical pharmaceutical/fine chemical operational process, and they are therefore responsible for most of the waste generated in the chemical industries and laboratories [23]. Nowadays, most solvents employed are substances derived from fossil fuels and have a negative impact on the health and the environment. In addition to water [24-27], biomass-derived chemicals are probably the most promising alternatives to replace these harmful solvents [19-22]. Its renewable origin and unique combination of physicochemical properties, such as high polarity, low toxicity and flammability, high boiling point, ability to form strong hydrogen bonds and to dissolve both organic and inorganic compounds (salts, acids, bases and transition metal complexes), make glycerol a good candidate to be employed as green reaction medium for synthetic chemistry [28]. This innovative way to revalorize glycerol has been very well received by the chemical community and a wide variety of organic reactions and synthetic methodologies have been successfully developed in this medium in recent years [29-33]. Remarkably, in some cases, the use of glycerol as solvent was found to enhance the effectiveness [34] and selectivity [35] of the reactions, and allowed easy product separation [36] and catalyst recycling [37]. 
Recent works have demonstrated that glycerol can also act both as solvent and hydrogen donor in metal-catalyzed transfer hydrogenation $(\mathrm{TH})$ reactions. $\mathrm{TH}$ is recognized as an efficient reduction method of unsaturated organic compounds (ketones, aldehydes, imines, olefins, etc.) and constitutes a safer alternative to the classical catalytic hydrogenations using highly flammable molecular hydrogen [38-42]. Replacing the most commonly employed hydrogen sources in TH reactions, i.e., 2-propanol or formic acid/triethylamine mixtures, by glycerol results not only economically appealing but also more environmentally friendly. Interest in $\mathrm{TH}$ processes from glycerol relates also with the concomitant formation of dihydroxyacetone (Scheme 2), the expected oxidized form of glycerol according to the primary and secondary alcohol oxidation potentials [43], due to the industrial relevance of this chemical [44]. The aim of the present review article is to provide a comprehensive account of the advances reached in the use of glycerol as solvent and hydrogen source in metal-catalyzed transfer hydrogenation of organic compounds. The utility of glycerol as solvent and reducing agent for the generation of metal nanoparticles is also highlighted.

Scheme 2. Generation of dihydroxyacetone from glycerol by transfer hydrogenation (TH).

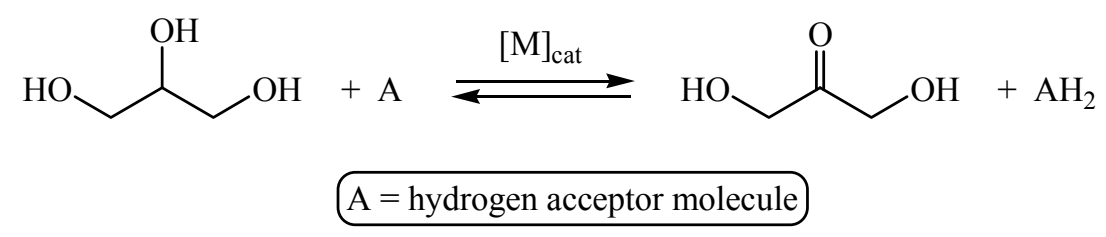

\section{Transfer Hydrogenation of Carbonyl Compounds in Glycerol}

The first report on TH in glycerol, published by Crotti and co-workers in 2009, examined the reduction of acetophenone by the iridium(I) derivatives $\left[\operatorname{Ir}\left(\eta^{4}-1,5\right.\right.$-hexadiene $\left.)(\mathrm{N}-\mathrm{N})\right][\mathrm{Cl}](\mathrm{N}-\mathrm{N}=$ 3,4,7,8-tetramethyl-1,10-phenanthroline (Me 4 phen), 4,7-dimethyl-1,10-phenanthroline ( $\left.\mathrm{Me}_{2} \mathrm{phen}\right)$, 4,4'-dimethyl-2,2'-bipyridine ( $\mathrm{Me}_{2}$ bipy), 2,2'-bipyridine (bipy)) [45]. The highest rate was achieved employing $\left[\operatorname{Ir}\left(\eta^{4}-1,5\right.\right.$-hexadiene $)\left(\mathrm{Me}_{2}\right.$ phen $\left.)\right][\mathrm{Cl}]$ associated with $\mathrm{K}_{2} \mathrm{CO}_{3}$ at $100{ }^{\circ} \mathrm{C}$, but conversion in 1-phenylethanol was quite modest (39\%) (Scheme 3). In addition, authors observed the gradual decomposition of the dihydroxyacetone formed, probably favored by the presence of base and the high temperature employed.

Scheme 3. Iridium-catalyzed transfer hydrogenation of acetophenone in glycerol.

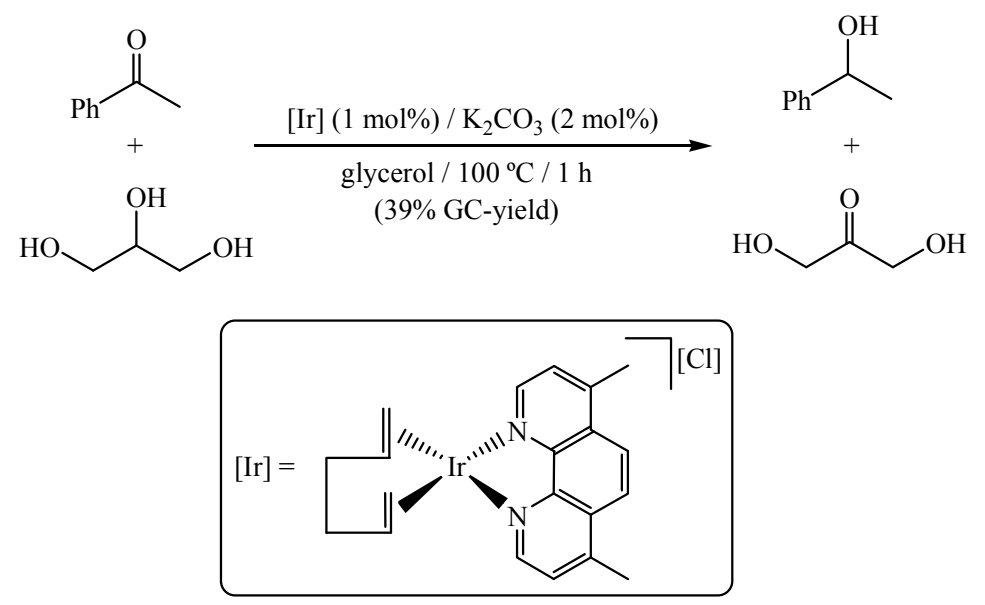


In order to minimize the decomposition of dihydroxyacetone, Crotti and co-workers also explored the ability of the iridium(I) complex 1 (Figure 1), previously described as an efficient catalyst for $\mathrm{TH}$ reactions under base-free conditions in isopropanolic media, to promote the reduction of acetophenone in glycerol [46]. Unfortunately, complex 1 turned out to be almost inactive (yields $<8 \%$ ). In contrast, when benzaldehyde, a more reactive carbonyl compound, was used as the starting material it could be reduced to benzyl alcohol under these base-free conditions, albeit with moderate conversion (up to $46 \%$ ). Once again, despite the absence of base, the dihydroxyacetone formed still underwent degradation, its final proportion being well below than that of benzyl alcohol (12\%-24\% vs. $18 \%-46 \%)$.

Figure 1. Structure of the iridium(I) complex 1.

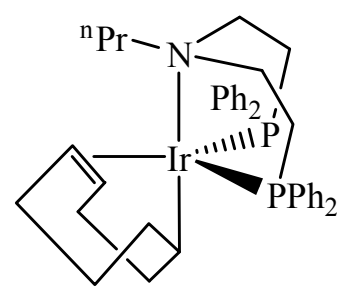

(1)

The hydrogen transfer from glycerol to benzaldehyde was also explored using a catalytic system composed of the ruthenium(II) dimer $\left[\left\{\mathrm{RuCl}(\mu-\mathrm{Cl})\left(\eta^{6}-p \text {-cymene }\right)\right\}_{2}\right]$ and $\mathrm{KOH}(2 \mathrm{~mol} \%$ of $\mathrm{Ru}$, $12 \mathrm{~mol} \%$ of base) [47]. Both conventional oil-bath heating $\left(70{ }^{\circ} \mathrm{C}\right)$ and microwaves (MW) irradiation (domestic oven, $900 \mathrm{~W}$ ) led to moderate yields in benzyl alcohol $(33 \%-48 \%)$ after $24 \mathrm{~h}$, and complete transformation of benzaldehyde could only be achieved by increasing the ruthenium loading to $25 \mathrm{~mol} \%$ [48]. In contrast, when the same reaction was performed under ultrasounds (US) irradiation, using a combination of $\mathrm{KOH}$ and $\mathrm{NaOH}$ (1-2 mol\%), quantitative formation of benzyl alcohol was achieved at $60{ }^{\circ} \mathrm{C}$ in $3 \mathrm{~h}$ with only $1 \mathrm{~mol} \%$ of $\left[\left\{\mathrm{RuCl}(\mu-\mathrm{Cl})\left(\eta^{6}-p \text {-cymene }\right)\right\}_{2}\right]$ (Scheme 4) [49]. The authors argued that, under sonochemical conditions, the dispersion of the base in glycerol is optimal and this would explain the shorter reaction time observed. In all these reactions, conversion of glycerol to dihydroxyacetone was proposed, but in no case experimental evidences of their detection and quantification were given.

Scheme 4. Ru-catalyzed TH of benzaldehyde in glycerol under sonochemical conditions.

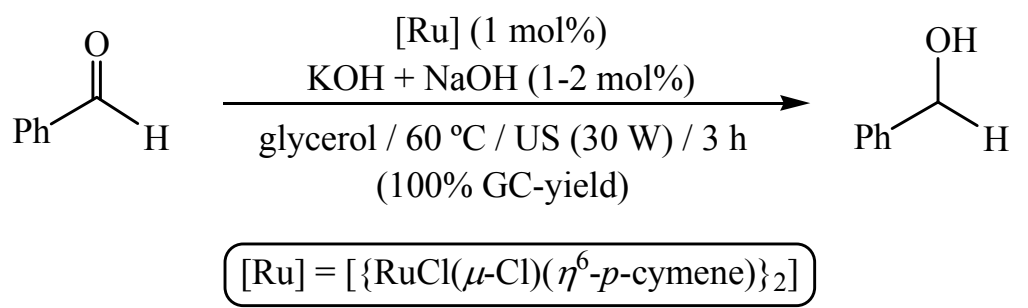

A series of $\operatorname{Ir}(\mathrm{III})$ and $\operatorname{Ir}(\mathrm{I})$ complexes containing $N$-heterocyclic carbene (NHC) ligands $\mathbf{2 - 5}$ (Figure 2) were studied by Mata and co-workers as potential catalysts for the transfer hydrogenation of carbonyl compounds in glycerol [50,51]. In the presence of $\mathrm{KOH}$ (1 equivalents), all of them ( $2.5 \mathrm{~mol} \%$ of Ir) were active in the reduction of acetophenone and benzaldehyde, leading to the desired alcohols in low to excellent yields after $7 \mathrm{~h}$ of heating in an oil-bath at $120{ }^{\circ} \mathrm{C}$ [51]. In general, the 
reduction of benzaldehyde proceeded with comparatively higher yields than benzophenone $(66 \%-99 \%$ vs. 25\%-80\%), with complexes 3 and 5a being particularly effective for the reduction of the former, and 3 and $\mathbf{4 b}$ for the latter. Under the same experimental conditions complex 3 was also able to reduce benzophenone in $91 \%$ yield, albeit a longer reaction time was in this case required [50]. In the search of activity improvements, the reduction of acetophenone and benzaldehyde by complexes 2-5 was studied using MW and US activation instead of classical oil-bath heating [51]. In particular, the use of ultrasounds had a tremendous impact in shortening the reaction times, and very good results were obtained in the reduction of benzaldehyde even with a lower iridium loading (e.g., 73\% yield of benzyl alcohol was achieved after $5 \mathrm{~min}$ using $1 \mathrm{~mol} \%$ of complex 4a). Again, optimal dispersion of the base in glycerol was evoked to explain the good results obtained under sonochemical conditions. However, we must note that partial decomposition of complexes $\mathbf{2}-\mathbf{5}$ into catalytically inactive $\operatorname{Ir}(0)$-containing nanoparticles was observed using MW and US techniques.

Figure 2. Structure NHC-based iridium catalysts 2-5.
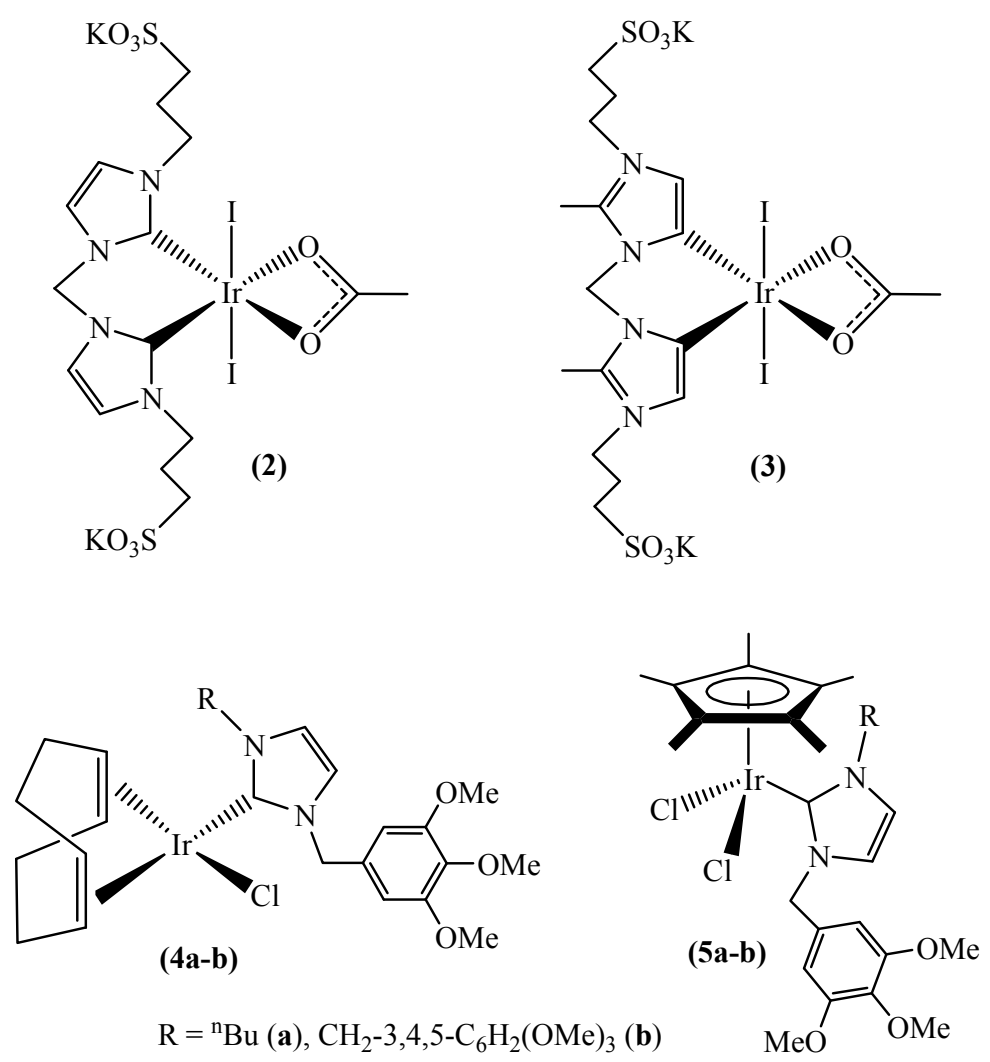

Quite recently, Gawande, Branco and co-workers have described an efficient heterogeneous catalyst, consisting of inexpensive ferrite-nickel magnetic nanoparticles $\left(\mathrm{Fe}_{3} \mathrm{O}_{4}-\mathrm{Ni} \mathrm{MNPs}\right)$, for the transfer hydrogenation of carbonyl compounds in glycerol (Scheme 5) [52]. This system (8.85 mol\% of $\mathrm{Ni}$ ), associated with $\mathrm{KOH}$ ( 2 equivalents), was able to convert selectively benzaldehyde, different acetophenone derivatives and cyclohexanone to the corresponding alcohols in good to excellent yields after heating the reaction mixtures at $80{ }^{\circ} \mathrm{C}$ for $2-2.5 \mathrm{~h}$. Remarkably, unlike the examples discussed above, no differences in reactivity between aldehyde and ketone functionalities were observed in this case. 
Scheme 5. TH of carbonyl compounds in glycerol using heterogeneous $\mathrm{Fe}_{3} \mathrm{O}_{4}$-Ni magnetic nanoparticles (MNPs).

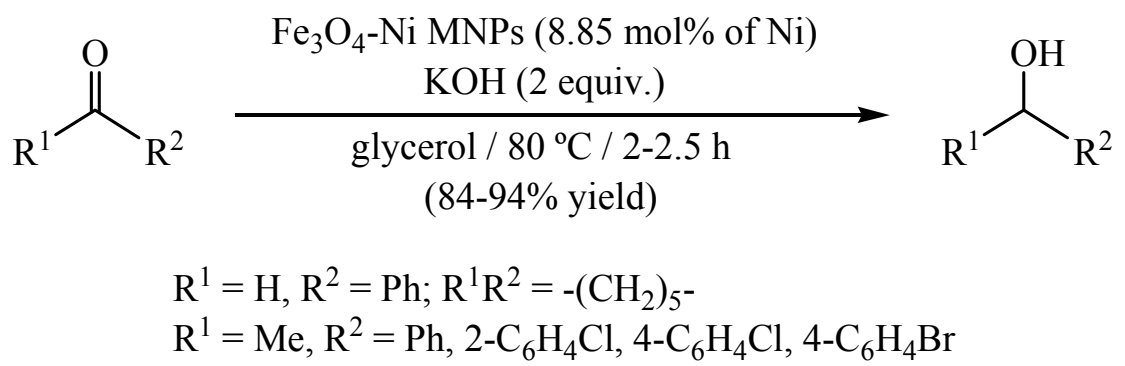

\section{Transfer Hydrogenation of Olefins in Glycerol}

First examples of the reduction of carbon-carbon double bonds in glycerol were described by Wolfson and co-workers in 2009 [48]. They found that palladium supported on carbon $(0.2-0.3 \mathrm{~mol} \%$ Pd) was able to hydrogenate quantitatively cyclohexene and styrene after $5-9 \mathrm{~h}$ of heating at $70{ }^{\circ} \mathrm{C}$ in pure glycerol (Scheme 6). However, bulky olefins (i.e., cis-stilbene and 1,1-diphenylethylene) and linear aliphatic alkenes (i.e., 1-hexene and 1-octene) were only partially reduced through this methodology (7\%-35\% yields) even under MW-irradiation [53]. The steric hindrance associated to the former, and the low solubility of the latter in glycerol, is behind these poorer results. It is noteworthy that, after extraction of the reaction product with diethyl ether (immiscible with glycerol), both the catalyst and glycerol could be recycled three times in the reduction of the model substrate cyclohexene, albeit with a slight decrease in activity after each cycle.

Scheme 6. Pd-catalyzed transfer hydrogenation of olefins in glycerol.

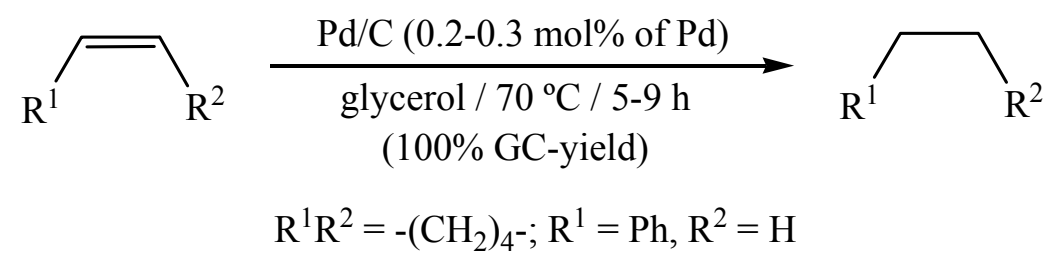

The iridium(III)-NHC complexes $\mathbf{2 - 3}$ proved to be also active in the TH of a variety of olefins by glycerol, although their effectiveness was in general only modest [50]. The most relevant results were obtained in the reduction of $\alpha, \beta$-unsaturated ketones, where an excellent chemoselectivity was observed. Thus, as shown in Scheme 7, the reduction of benzylideneacetone was very selective in the production of the saturated ketone 4-phenyl-2-butanone, and only traces of the fully hydrogenated compound (i.e., 4-phenyl-2-butenol) were detected. For dibenzylideneacetone, again the hydrogenation of one of the olefinic bonds was more favorable than the reduction of the ketone group, which was in this case not observed. These results contrast with the reduction of cinnamaldehyde for which the TH of the $\mathrm{C}=\mathrm{C}$ bond is followed by the rapid reduction of the carbonyl group, so that the major final product is the saturated alcohol 3-phenyl-1-propanol. Overall, the reactions depicted in Scheme 7 are in complete accord with the greater tendency shown by the $\operatorname{Ir}(\mathrm{III})$ complexes $\mathbf{2}-\mathbf{3}$ to reduce aldehydes over ketones. TH of phenylacetylene by complexes $\mathbf{2}-\mathbf{3}$ in glycerol was also explored, but styrene was formed in very low yields $\left(12 \%-30 \%\right.$ after $14 \mathrm{~h}$ at $120{ }^{\circ} \mathrm{C}$ with $2.5 \mathrm{~mol} \%$ of $\mathbf{2}-\mathbf{3}$ and 1 equivalent of 
$\mathrm{KOH})$. As in the preceding cases, conversion of glycerol to dihydroxyacetone was proposed without experimental confirmation.

Scheme 7. Ir-catalyzed transfer hydrogenation of $\alpha, \beta$-unsaturated carbonyl compounds in glycerol.

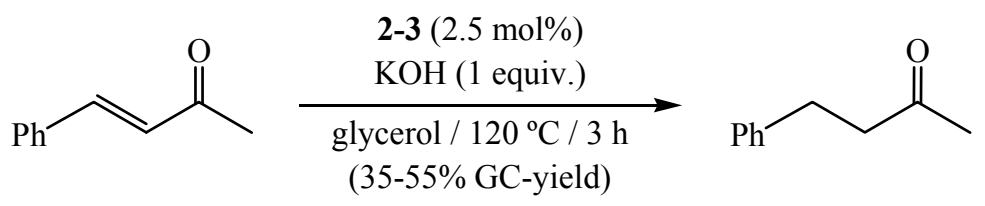<smiles>O=C(/C=C/c1ccccc1)c1ccccc1</smiles>

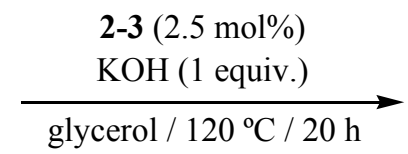<smiles>O=C(/C=C/c1ccccc1)CCc1ccccc1</smiles>

(77-80\% GC-yield)<smiles>O=C/C=C/c1ccccc1</smiles>

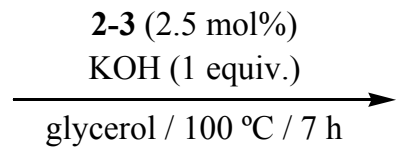<smiles>OCCCc1ccccc1</smiles>

(49-70\% GC-yield)

Reduction of the $\mathrm{C}=\mathrm{C}$ bond of allylic alcohols in both pharmaceutical (99.5\% purity) and technical (87\% purity) grade glycerol has been described employing a family of arene-ruthenium(II) complexes $\left[\mathrm{RuCl}_{2}\left(\eta^{6}\right.\right.$-arene $\left.) \mathrm{L}\right]$ (arene $=\mathrm{C}_{6} \mathrm{H}_{6}, p$-cymene, mesitylene, $\mathrm{C}_{6} \mathrm{Me}_{6} ; \mathrm{L}=$ hydrophilic phosphine ligand) as catalysts [54]. Among them, the best results were obtained with $\left[\mathrm{RuCl}_{2}\left(\eta^{6}-\mathrm{C}_{6} \mathrm{H}_{6}\right)\right.$ (DAPTA)] (6; DAPTA $=$ 3,7-diacetyl-1,3,7-triaza-5-phosphabicyclo[3.3.1]nonane), which associated with KOH was able to generate the desired saturated alcohols in high yields (up to $90 \%$ after $6-15 \mathrm{~h}$ of heating at $100{ }^{\circ} \mathrm{C}$ ) regardless of the purity of the solvent employed (Scheme 8 ). We must note that this reduction process does not involve a direct transfer of hydrogen from glycerol to the $\mathrm{C}=\mathrm{C}$ bond of the substrate, but the initial redox-isomerization of the allylic alcohol through $\mathrm{C}=\mathrm{C}$ bond migration and subsequent transfer hydrogenation of the resulting carbonyl compound. Remarkably, contrary to previous studies carried out in water and 2-propanol [55,56], the use of glycerol as the reaction medium enabled the recycling of the catalyst (up to four consecutive runs).

Scheme 8. Ruthenium-catalyzed reduction of allylic alcohols in glycerol.
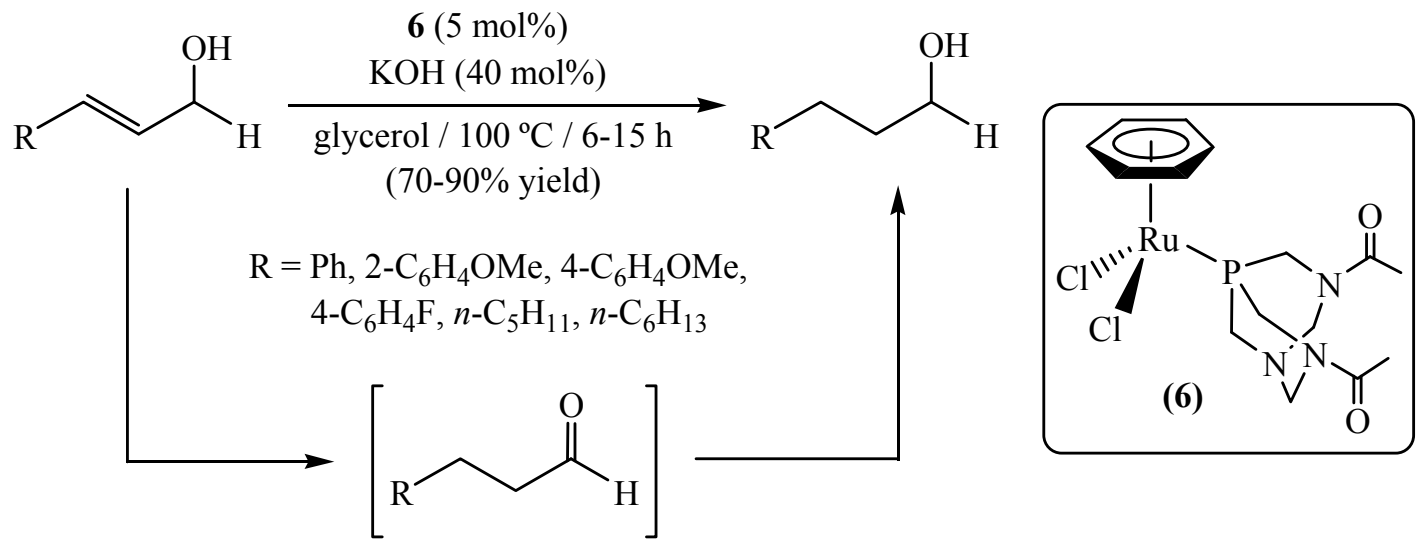
In addition to these examples, reduction of linoleic to oleic acid was found to occur during the hydrolysis of soybean oil and tallow using nickel catalysts supported on alumina, effect that was best manifested under $3 \mathrm{~h}$ of reaction at $250-270{ }^{\circ} \mathrm{C}$ with $\mathrm{NiO} / \mathrm{Al}_{2} \mathrm{O}_{3}$ as catalyst (Scheme 9) [57]. The glycerol formed during the hydrolysis of the triglycerides behaves as the hydrogen donor, allowing the reduction of the in-situ produced di-unsaturated fatty acid into the mono-unsaturated one.

Scheme 9. Transformation of linoleic acid to oleic acid by catalytic TH from glycerol.

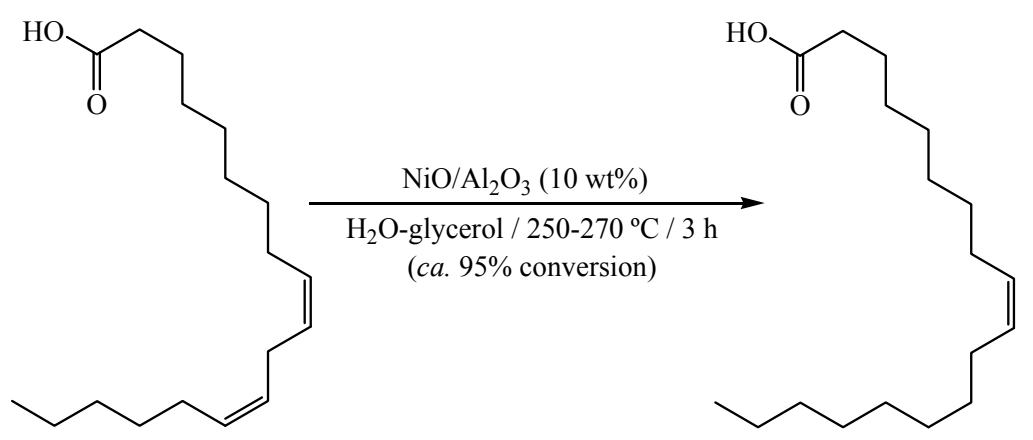

\section{Transfer Hydrogenation of Nitroarenes in Glycerol}

Selective reduction of nitroarenes is an important synthetic tool for the preparation of aromatic amines in organic chemistry. The reduction of nitro aromatic compounds is also of considerable interest because these chemicals are common groundwater contaminants and reduction reactions can play a central role in their environmental fate or cleanup. Many methods have been reported in the literature for the reduction of nitroaromatics, including the use of Raney nickel under TH conditions. In this context, Wolfson and co-workers have demonstrated that the reduction of various nitrobenzene derivatives by means of Raney Ni can be performed using glycerol as the solvent and hydrogen donor $[48,58]$. Reactions, which were typically performed with a stoichiometric amount of Raney Ni and excess of $\mathrm{NaOH}$ (2.5 equivalents), delivered the desired anilines in moderate to good yields $(44 \%-81 \%)$ after $24 \mathrm{~h}$ of heating at $100{ }^{\circ} \mathrm{C}$, with those substrates containing electron-withdrawing substituents being reduced more easily than those with electron-donating groups.

Scheme 10. Transfer hydrogenation of nitroarenes in glycerol using magnetic $\mathrm{Fe}_{3} \mathrm{O}_{4}$-Ni nanoparticles.

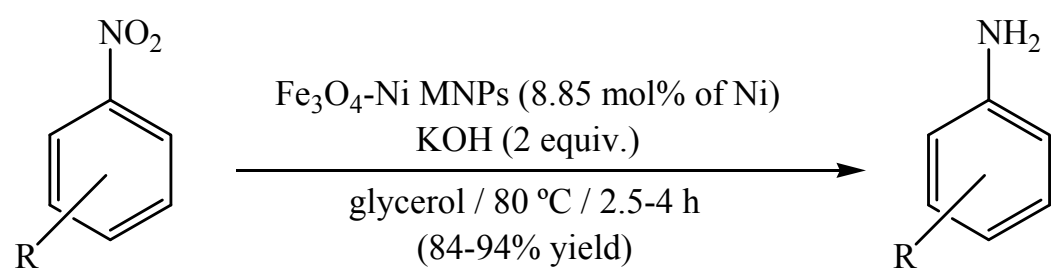

$$
\begin{aligned}
\mathrm{R}= & \mathrm{H}, 2-\mathrm{Me}, 3-\mathrm{Me}, 2-\mathrm{OMe}, 3-\mathrm{OMe}, 4-\mathrm{OMe}, 2-\mathrm{Cl}, 3-\mathrm{Cl}, 3-\mathrm{Br}, 4-\mathrm{Br} \\
& 4-\mathrm{F}, 2,5-\mathrm{Cl}_{2}, 4-\mathrm{OH}, 2-\mathrm{NH}_{2}, 3-\mathrm{NO}_{2}, 4-\mathrm{CN}, 4-\mathrm{CO}_{2} \mathrm{Et}, 4-\mathrm{C}(=\mathrm{O}) \mathrm{Me}
\end{aligned}
$$

Much faster transformations were subsequently described, under milder reaction conditions, using $\mathrm{Fe}_{3} \mathrm{O}_{4}$-Ni MNPs as catalyst in combination with $\mathrm{KOH}$ (Scheme 10) [52]. Contrary to the preceding case, the electronic nature of the substituents on the aromatic ring did not have a significant influence 
on the effectiveness of the process. This heterogeneous system also showed an exquisite chemoselectivity, reducing only the nitro group even in the presence of carbonyl functionalities. A stronger interaction of the nitro group to the catalyst surface compared to the carbonyl one was evoked to explain the chemoselectivity observed. It is also worthy of note that, starting from 1,3-dinitrobenzene, selective reduction of only one $\mathrm{NO}_{2}$ functionality took place under the standard reaction conditions. In addition, after separation using a simple magnet, the $\mathrm{Fe}_{3} \mathrm{O}_{4}-\mathrm{Ni} \mathrm{MNPs}$ could be reused eight times without any significant loss in catalytic activity and selectivity. Overall, this new methodology represents a real improvement with respect to classical methods based on the use of more expensive and hardly recyclable Raney nickel or Pd and Pt catalysts.

\section{Transfer Hydrogenation of Other Organic Molecules in Glycerol}

In a recent patented work [59], a method for the preparation of primary alcohols by transfer hydrogenation of carboxylic acids in glycerol has been disclosed (Scheme 11). The reactions, which were performed at $140-150{ }^{\circ} \mathrm{C}$ in the presence of inexpensive $\mathrm{CoCl}_{2} \cdot 6 \mathrm{H}_{2} \mathrm{O}$ as catalyst and $\mathrm{KOH}$, delivered the alcohols in a selective manner, and in excellent yields, after a very short reaction period. This new method represents a good alternative to the classical ones involving the use of molecular hydrogen or $\mathrm{NaBH}_{4}$.

Scheme 11. Transfer hydrogenation of carboxylic acids in glycerol.

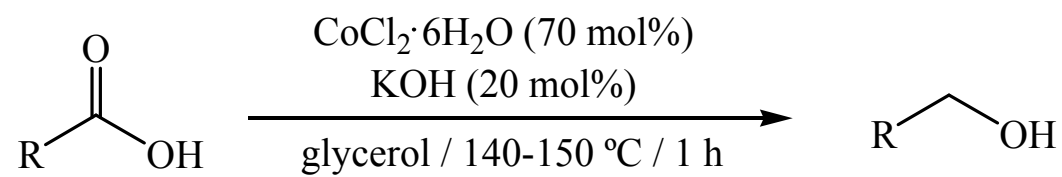

(90-95\% yield)

$\mathrm{R}=\mathrm{Ph}, n-\mathrm{C}_{3} \mathrm{H}_{7}, n-\mathrm{C}_{4} \mathrm{H}_{9}, n-\mathrm{C}_{5} \mathrm{H}_{11}, n-\mathrm{C}_{6} \mathrm{H}_{13}, n-\mathrm{C}_{7} \mathrm{H}_{15}, n-\mathrm{C}_{8} \mathrm{H}_{17}$

Aqueous glycerol in the presence of the ruthenium(II) catalyst $\left[\mathrm{RuCl}_{2}\left(\mathrm{PPh}_{3}\right)_{3}\right]$ and $\mathrm{KOH}$ behaved also as a $\mathrm{H}$-donor to $\mathrm{CO}_{2}$, thus producing formic acid $\left(\mathrm{HCO}_{2} \mathrm{H}\right)($ Scheme 12) [60]. As determined by ${ }^{1} \mathrm{H}$ and ${ }^{13} \mathrm{C}$ NMR spectroscopy, glycerol was selectively converted into glycolic acid $\left(\mathrm{HOCH}_{2} \mathrm{CO}_{2} \mathrm{H}\right)$ by decomposition of the initially formed dihydroxyacetone. Such a decarbonylation process is catalyzed by ruthenium under the basic conditions employed. Unfortunately, in contrast to previous examples employing 2-propanol as the hydrogen source [61], turnover numbers (TON) no higher than a few units could be achieved in this reaction that elegantly transforms two waste products into value-added chemicals.

Scheme 12. Transfer hydrogenation of $\mathrm{CO}_{2}$ by aqueous glycerol.

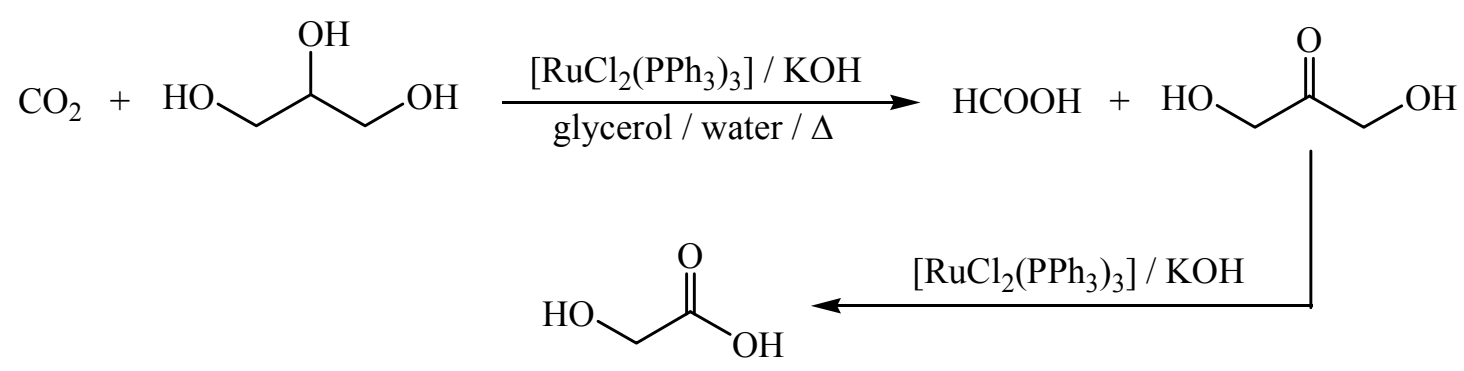


Finally, in the context of a broad study, glycerol was very recently evaluated as a potential hydrogen-donating solvent for the hydrogenolytic depolymerization of lignin, using nickel nanoparticles supported on the mesoporous silica AI-SBA-15 as catalyst under microwave irradiation [62]. After three hours of irradiation at $150{ }^{\circ} \mathrm{C}, c a .25 \mathrm{wt} \%$ of the initial lignin was converted into the desired bio-oil (a mixture of the monomeric phenolic products syringol, vanillin, syringaldehyde and acetosyringone). This result was superior to that found using 2-propanol as the hydrogen source (ca. $2 \mathrm{wt} \%$ of bio-oil), but slightly poorer in comparison to that reached in formic acid (ca. $30 \mathrm{wt} \%$ of bio-oil), the best $\mathrm{H}$-donor solvent found in the study. We must also note that, contrary to the case of formic acid, undesirable formation of char was also observed in glycerol (ca. $40 \mathrm{wt} \%$ ).

\section{Glycerol as Solvent and Reductant for the Formation of Metal Nanoparticles}

During the last decade there has been extensive research into the synthesis of metal nanoparticles by the so-called polyol process, where a polyalcohol, generally coupled with a base, acts not only as a solvent but also as a mild reducing agent for the reduction of metal salt precursors [63]. In this context, glycerol has been successfully employed in the preparation of a variety of Ag [64-71], Tl [64], Pd [67,72], Pt [67,73,74], Ru [67], Au [75], Pt-Ru [74], Pt-Pd [76-78] and Co-Se [79] nanoparticles with various morphologies. Similarly, uniform $\mathrm{Mn}(\mathrm{OH})_{2}$ and $\mathrm{MnCO}_{3}$ nanocrystals with diameters of ca. 20 and $60 \mathrm{~nm}$, respectively, and $\mathrm{VO}_{2}(\mathrm{~B})$ nanoflakes could be obtained from $\mathrm{KMnO}_{4}$ [80] and $\mathrm{V}_{2} \mathrm{O}_{5}[81]$ using glycerol as solvent and reductant.

Quite recently, diameter-controlled (50-200 nm) Ag nanowires were also fabricated from $\mathrm{AgNO}_{3}$ in glycerol under non-stirred microwave irradiation conditions [82]. Sodium dodecyl sulphate (SDS) was used to prevent the growth of the diameter, which could be finely controlled by changing the amounts of $\mathrm{AgNO}_{3}$, glycerol and SDS.

We must note that in comparison with more classical polyols, such as ethylene glycol or propylene glycol, the use glycerol as solvent and reducing agent for metal nanoparticles formation is clearly more convenient because of its lower cost and toxicity.

\section{Conclusions and Perspectives}

In summary, we have discussed the advent and progress on the use of glycerol as solvent and hydrogen donor for transfer hydrogenation reactions. Although the current body of work in the field is still very limited, from the studies published in the last three years it becomes apparent that this waste generated by the biodiesel industry can be a reliable alternative to replace 2-propanol in the near future. To achieve this goal, the design of new metal catalysts, more effective under milder reaction conditions, is needed. We hope that an increasing number of scientists will explore this interesting and young research field and find broad application of glycerol as economically appealing and environmentally friendly hydrogen-donor solvent for $\mathrm{TH}$ reactions. In particular, the challenging reduction of $\mathrm{CO}_{2}$ by glycerol should be studied in deep since, by means of this reaction, two waste products, whose production increases day by day, could be easily revalorized into useful highly value-added chemicals. In this sense, owing to the relevant results described recently by Gawande, Branco and co-workers [52], the use of tailored nanocatalysts should play a key role to achieve 
success. An increase in the use of glycerol for the production of new nanomaterials is also expected in the near future.

\section{Acknowledgments}

Financial support from the "Ministerio de Economía y Competitividad" of Spain (Projects CTQ2010-14796/BQU and CSD2007-00006) is gratefully acknowledged. The authors are also grateful to Pascale Crochet for her useful comments, suggestions and revisions during the preparation of this manuscript.

\section{Conflict of Interest}

The authors declare no conflict of interest.

\section{References}

1. Zhou, C.-H.; Beltramini, J.N.; Fan, Y.-X.; Lu, G.Q. Chemoselective catalytic conversion of glycerol as a biorenewable source to valuable commodity chemicals. Chem. Soc. Rev. 2008, 37, 527-549.

2. Pagliaro, M.; Rossi, M. The Future of Glycerol: New Usages for a Versatile Raw Material, 2nd ed.; RSC Publishing: Cambridge, UK, 2010.

3. Pagliaro, M.; Ciriminna, R.; Kimura, H.; Rossi, M.; Pina, C.D. From glycerol to value-added products. Angew. Chem. Int. Ed. 2007, 46, 4434-4440.

4. Corma, A.; Iborra, S.; Velty, A. Chemical routes for the transformation of biomass into chemicals. Chem. Rev. 2007, 107, 2411-2502.

5. Johnson, D.T.; Taconi, K.A. The glycerin glut: Options for the value-added conversion of crude glycerol resulting from biodiesel production. Environ. Prog. 2007, 26, 338-348.

6. Jérôme, F.; Pouilloux, Y.; Barrault, J. Rational design of solid catalysts for the selective use of glycerol as a natural organic building block. ChemSusChem 2008, 1, 586-613.

7. Behr, A.; Eilting, J.; Irawadi, K.; Leschinski, J.; Lindner, F. Improved utilisation of renewable resources: New important derivatives of glycerol. Green Chem. 2008, 10, $13-30$.

8. Pagliaro, M.; Ciriminna, R.; Kimura, H.; Rossi, M.; Pina, C.D. Recent advances in the conversion of bioglycerol into value-added products. Eur. J. Lipid Sci. Technol. 2009, 111, 788-799.

9. Da Silva, G.P.; Mack, M.; Conteiro, J. Glycerol: A promising and abundant carbon source for industrial microbiology. Biotechnol. Adv. 2009, 27, 30-39.

10. Mota, C.J.A.; da Silva, C.X.A.; Gonçalves, V.L.C. Glycerochemistry: New products and processes from glycerin of biodiesel production. Quim. Nova 2009, 32, 639-648.

11. Jérôme, F.; Barrault, J. Use of hybrid organic-siliceous materials for the selective conversion of glycerol. Eur. J. Lipid Sci. Technol. 2011, 113, 118-134.

12. Billamboz, M.; Lageay, J.C.; Hapiot, F.; Monflier, E.; Len, C. Novel strategy for the bisbutenolide synthesis via ring-closing metathesis. Synthesis 2012, 14, 137-143.

13. Vaidya, P.D.; Rodrigues, A.E. Glycerol reforming for hydrogen production: A review. Chem. Eng. Technol. 2009, 32, 1463-1469. 
14. Adhikari, S.; Fernando, S.D.; Haryanto, A. Hydrogen production from glycerol: An update. Energy Convers. Manage. 2009, 50, 2600-2604.

15. Nahar, G.; Dupont, V. Hydrogen via stream reforming of liquid biofeedstock. Biofuels 2012, 3, 167-191.

16. Rahmat, N.; Abdullah, A.Z.; Mohamed, A.R. Recent progress on innovative and potential technologies for glycerol transformation into fuel additives: A critical review. Renew. Sustain. Energy Rev. 2010, 14, 987-1000.

17. Anastas, P.T.; Warner, J.C. Green Chemistry: Theory and Practice; Oxford University Press: Oxford, UK, 1998.

18. Lancaster, M. Green Chemistry: An Introductory Text, 2nd ed.; RSC Publishing: Cambridge, UK, 2010.

19. Nelson, W.M. Green Solvents for Chemistry: Perspectives and Practice; Oxford University Press: New York, NY, USA, 2003.

20. Clark, J.H.; Taverner, S.J. Alternatives solvents: Shades of green. Org. Process Res. Dev. 2007, 11, 149-155.

21. Kerton, F.M. Alternative Solvents for Green Chemistry; RSC Publishing: Cambridge, UK, 2009.

22. Jessop, P.G. Searching for green solvents. Green Chem. 2011, 13, 1391-1398.

23. Constable, D.J.C.; Jimenez-Gonzalez, C.; Henderson, R.K. Perspective on solvent use in the pharmaceutical industry. Org. Process Res. Dev. 2007, 11, 133-137.

24. Li, C.-J.; Chen, L. Organic chemistry in water. Chem. Soc. Rev. 2006, 35, 68-82.

25. Li, C.-J. The development of catalytic nucleophilic additions of terminal alkynes in water. Acc. Chem. Res. 2010, 43, 581-590.

26. Gawande, M.B.; Branco, P.S. An efficient and expeditious Fmoc protection of amines and amino acids in aqueous media. Green Chem. 2011, 13, 3355-3359.

27. García-Álvarez, R.; Crochet, P.; Cadierno, V. Metal-catalyzed amide bond forming reactions in an environmentally friendly aqueous medium: Nitrile hydrations and beyond. Green Chem. 2013, 15, 46-66.

28. Wolfson, A.; Dlugy, C.; Shotland, Y. Glycerol as a green solvent for high product yields and selectivities. Environ. Chem. Lett. 2007, 5, 67-71.

29. Gu, Y.; Jérôme, F. Glycerol as a sustainable solvent for green chemistry. Green Chem. 2010, 12, 1127-1138.

30. Díaz-Álvarez, A.E.; Francos, J.; Lastra-Barreira, B.; Crochet, P.; Cadierno, V. Glycerol and derived solvents: New sustainable reaction media for organic synthesis. Chem. Commun. 2011, $47,6208-6227$.

31. Wolfson, A.; Dlugy, C.; Tavor, D. Glycerol-based solvents in organic synthesis. Trends Org. Chem. 2011, 15, 41-50.

32. Calvino-Casilda, V. Glycerol as an Alternative Solvent for Organic Reactions. In Green Solvents I: Properties and Applications in Chemistry; Ali Mohammad, Inamuddin, Eds.; Springer Science \& Business Media: Dordrecht, The Netherlands, 2012; pp. 187-207.

33. Wolfson, A.; Tavor, D.; Cravotto, G. Is Glycerol a Sustainable Reaction Medium? In Glycerol: Production, Structure and Applications; Silva, S., Ferreira, C., Eds.; Nova Science Publishers: New York, NY, USA, 2012; pp. 233-248. 
34. Safaei, H.R.; Shekouhy, M.; Rahmanpur, S.; Shirinfeshan, A. Glycerol as a biodegradable and reusable promoting medium for the catalyst-free one-pot three component synthesis of $4 \mathrm{H}$-pyrans. Green Chem. 2012, 14, 1696-1704.

35. Gu, Y.; Barrault, J.; Jérôme, F. Glycerol as an efficient promoting medium for organic reactions. Adv. Synth. Catal. 2008, 350, 2007-2012.

36. Wolfson, A.; Snezhko, A.; Meyouhas, T.; Tavor, D. Glycerol derivatives as green reaction mediums. Green Chem. Lett. Rev. 2012, 5, 7-12.

37. Francos, J.; Cadierno, V. Palladium-catalyzed cycloisomerization of ( $Z$ )-enynols into furans using green solvents: Glycerol vs. water. Green Chem. 2010, 12, 1552-1555.

38. Zassinovich, G.; Mestroni, G.; Gladiali, S. Asymmetric hydrogen transfer reactions promoted by homogeneous transition metal catalysts. Chem. Rev. 1992, 92, 1051-1069.

39. Gladiali, S.; Alberico, E. Asymmetric transfer hydrogenation: Chiral ligands and applications. Chem. Soc. Rev. 2006, 35, 226-236.

40. Samec, J.S.M.; Bäckvall, J.-E.; Andersson, P.G.; Brandt, P. Mechanistic aspects of transition metal-catalyzed hydrogen transfer reactions. Chem. Soc. Rev. 2006, 35, 237-248.

41. Gladiali, S.; Taras, R. Reduction of Carbonyl Compounds by Hydrogen Transfer. In Modern Reduction Methods; Andersson, P.G., Munslow, I.J., Eds.; Wiley-VCH: Weinheim, Germany, 2008; pp. 135-158.

42. Wills, M. Imino Reductions by Transfer Hydrogenation. In Modern Reduction Methods; Andersson, P.G., Munslow, I.J., Eds.; Wiley-VCH: Weinheim, Germany, 2008; pp. 271-296.

43. Adkins, H.; Elofson, R.M.; Rossow, A.G.; Robinson, C.C. The oxidation potentials of aldehydes and ketones. J. Am. Chem. Soc. 1949, 71, 3622-3629.

44. Katryniok, B.; Kimura, H.; Skrzyńska, E.; Girardon, J.-S.; Fongarland, P.; Capron, M.; Ducoulombier, R.; Mimura, N.; Paula, S.; Dumeignil, F. Selective catalytic oxidation of glycerol: Perspectives for high value chemicals. Green Chem. 2011, 13, 1960-1979.

45. Farnetti, E.; Kašpar, J.; Crotti, C. A novel glycerol valorization route: Chemoselective dehydrogenation catalyzed by iridium derivatives. Green Chem. 2009, 11, 704-709.

46. Crotti, C.; Kašpar, J.; Farnetti, E. Dehydrogenation of glycerol to hydroxyacetone catalyzed by iridium complexes with P-N ligands. Green Chem. 2010, 12, 1295-1300.

47. Tavor, D.; Sheviev, O.; Dlugy, C.; Wolfson, A. Tranfer hydrogenations of benzaldehyde using glycerol as solvent and hydrogen source. Can. J. Chem. 2010, 88, 305-308.

48. Wolfson, A.; Dlugy, C.; Shotland, Y.; Tavor, D. Glycerol as solvent and hydrogen donor in transfer hydrogenation-dehydrogenation reactions. Tetrahedron Lett. 2009, 50, 5951-5953.

49. Cravotto, G.; Orio, L.; Gaudino, E.C.; Martina, K.; Tavor, D.; Wolfson, A. Efficient synthetic protocols in glycerol under heterogeneous conditions. ChemSusChem 2011, 4, 1130-1134.

50. Azua, A.; Mata, J.A.; Peris, E. Iridium NHC based catalysts for transfer hydrogenation processes using glycerol as solvent and hydrogen donor. Organometallics 2011, 30, 5532-5536.

51. Azua, A.; Mata, J.A.; Peris, E.; Lamaty, F.; Martinez, J.; Colacino, E. Alternative energy input for transfer hydrogenation using iridium NHC based catalysts in glycerol as hydrogen donor and solvent. Organometallics 2012, 31, 3911-3919. 
52. Gawande, M.B.; Rathi, A.K.; Branco, P.S.; Nogueira, I.D.; Velhinho, A.; Shrikhande, J.J.; Indulkar, U.U.; Jayaram, R.V.; Ghumman, C.A.A.; Bundaleski, N.; et al. Regio- and chemoselective reduction of nitroarenes and carbonyl compounds over recyclable magnetic ferrite-nickel nanoparticles $\left(\mathrm{Fe}_{3} \mathrm{O}_{4}-\mathrm{Ni}\right)$ by using glycerol as a hydrogen source. Chem. Eur. J. 2012, 18, 12628-12632.

53. Tavor, D.; Popov, S.; Dlugy, C.; Wolfson, A. Catalytic transfer hydrogenation of olefins in glycerol. Org. Commun. 2010, 3, 70-75.

54. Díaz-Álvarez, A.E.; Crochet, P.; Cadierno, V. Ruthenium-catalyzed reduction of allylic alcohols using glycerol as solvent and hydrogen donor. Catal. Commun. 2011, 13, 91-96.

55. Cadierno, V.; Francos, J.; Gimeno, J.; Nebra, N. Ruthenium-catalyzed reduction of allylic alcohols: An efficient isomerization/transfer hydrogenation tandem process. Chem. Commun. 2007, 2536-2538.

56. Cadierno, V.; Crochet, P.; Francos, J.; García-Garrido, S.E.; Gimeno, J.; Nebra, N. Ruthenium-catalyzed isomerization/transfer hydrogenation in organic and aqueous media: A one-pot tandem process for the reduction of allylic alcohols. Green Chem. 2009, 11, 1992-2000.

57. Díaz, G.C.; Perez, R.S.; Tapanes, N.C.O.; Aranda, D.A.G.; Arceo, A.A. Hydrolysis-hydrogenation of soybean oil and tallow. Nat. Sci. 2011, 3, 530-534.

58. Tavor, D.; Gefen, I.; Dlugy, C.; Wolfson, A. Transfer hydrogenations of nitrobenzene using glycerol as solvent and hydrogen donor. Synth. Commun. 2011, 41, 3409-3416.

59. Chung, W.J.; Baskar, C.; Chung, D.G.; Han, M.D.; Lee, C.H. Catalytic Transfer Hydrogenation of Carboxylic Acids to Their Corresponding Alcohols by Using Glycerol as Hydrogen Donor. Repub. Korean Kongkae Taeho Kongbo Patent KR 2012006276, 18 January 2012.

60. Dibenedetto, A.; Stufano, P.; Nocito, F.; Aresta, M. Ru ${ }^{\mathrm{II}}$-mediated hydrogen transfer from aqueous glycerol to $\mathrm{CO}_{2}$ : From waste to value-added products. ChemSusChem 2011, 4, 1311-1315.

61. Sanz, A.; Azua, A.; Peris, E. " $\left(\eta^{6}\right.$-arene)Ru(bis-NHC)" complexes for the reduction of $\mathrm{CO}_{2}$ to formate with hydrogen and by transfer hydrogenation with $i \mathrm{PrOH}$. Organometallics 2010, 39, 6339-6343.

62. Toledano, A.; Serrano, L.; Labidi, J.; Pineda, A.; Balu, A.M.; Luque, R. Heterogeneously catalysed mild hydrogenolytic depolymerisation of lignin under microwave irradiation with hydrogen-donating solvents. ChemCatChem 2012, doi:10.1002/cctc.201200616.

63. Carroll, K.J.; Reveles, J.U.; Shultz, M.D.; Khanna, S.N.; Carpenter, E.E. Preparation of elemental $\mathrm{Cu}$ and Ni nanoparticles by the polyol method: An experimental and theoretical approach. J. Phys. Chem. C 2011, 115, 2656-2664 and references cited therein.

64. Rele, M.; Kapoor, S.; Sharma, G.; Mukherjee, T. Reduction and aggregation of silver and thallium ions in viscous media. Phys. Chem. Chem. Phys. 2004, 6, 590-595.

65. Ullah, M.H.; Kim, I.; Ha, C.-S. In-situ preparation of binary-phase silver nanoparticles at a high $\mathrm{Ag}^{+}$concentration. J. Nanosci. Nanotechnol. 2006, 6, 777-782.

66. Ullah, M.H.; Kim, I.; Ha, C.-S. Preparation and optical properties of silver nanoparticles at a high $\mathrm{Ag}^{+}$concentration. Mater. Lett. 2006, 60, 1496-1501.

67. Grace, A.N.; Pandian, K. One pot synthesis of polymer protected Pt, Pd, Ag and Ru nanoparticles and nanoprisms under reflux and microwave mode of heating in glycerol-A comparative study. Mat. Chem. Phys. 2007, 104, 191-198. 
68. Sarkar, A.; Kapoor, S.; Mukherjee, T. Synthesis and characterization of silver nanoparticles in viscous solvents and its transfer into non-polar solvents. Res. Chem. Intermed. 2010, 36, 411-421.

69. Dzido, G.; Jarzębski, A.B. Fabrication of silver nanoparticles in a continuous flow, low temperature microwave-assisted polyol process. J. Nanopart. Res. 2011, 13, 2533-2541.

70. Preuksarattanawut, T.; Asavavisithchai, S.; Nisaratanoporn, E. Fabrication of silver hollow microspheres by sodium hydroxide in glycerol solution. Mat. Chem. Phys. 2011, 130, 481-486.

71. Garcia, A.C.; Gasparotto, L.H.S.; Gomes, J.F.; Tremiliosi-Filho, G. Straightforward synthesis of carbon-supported Ag nanoparticles and their application for the oxygen reduction reaction. Electrocatalysis 2012, 3, 147-152.

72. Lee, Y.-W.; Han, S.-B.; Ko, A.R.; Kim, H.-S.; Park, K.-W. Glycerol-mediated synthesis of Pd nanostructures with dominant $\{111\}$ facets for enhanced electrocatalytic activity. Catal. Commun. 2011, 15, 137-140.

73. Koo, M.; Bae, J.-S.; Kim, H.-C.; Nam, D.-G.; Ko, C.H.; Yeum, J.H.; Oh, W. Electrochemical oxidation of some basic alcohols on multiwalled carbon nanotube-platinum composites. Bull. Mater. Sci. 2012, 35, 545-550.

74. Selvaraj, V.; Vinoba, M.; Alagar, M. Electrocatalytic oxidation of ethylene glycol on Pt and Pt-Ru nanoparticles modified multi-walled carbon nanotubes. J. Colloid Interf. Sci. 2008, 322, 537-544.

75. Gasparotto, L.H.S.; Garcia, A.C.; Gomes, J.F.; Tremiliosi-Filho, G. Electrocatalytic performances of environmentally friendly synthesized gold nanoparticles towards the borohydride electro-oxidation reaction. J. Power Sources 2012, 218, 73-78.

76. Lee, Y.-W.; Oh, S.-E.; Park, K.-W. Highly active Pt-Pd alloy catalyst for oxygen reduction reaction in buffer solution. Electrochem. Commun. 2011, 13, 1300-1303.

77. Lee, Y.-W.; Ko, A.-R.; Han, S.-B.; Kim, H.-S.; Park, K.-W. Synthesis of octahedral Pt-Pd alloy nanoparticles for improved catalytic activity and stability in methanol electrooxidation. Phys. Chem. Chem. Phys. 2011, 13, 5569-5572.

78. Lee, Y.-W.; Ko, A.-R.; Kim, D.-Y.; Han, S.-B.; Park, K.-W. Octahedral Pt-Pd alloy catalysts with enhanced oxygen reduction activity and stability in proton exchange membrane fuel cells. RSC Adv. 2012, 2, 1119-1125.

79. Nekooi, P.; Ahmadi, R.; Amini, M.K. Preparation of CoSe nanoparticles by microwave-assisted polyol method: Effect of Se/Co ratio, support type and synthesis conditions on oxygen reduction activity. J. Iran Chem. Soc. 2012, 9, 715-722.

80. Wang, X.; Li, Y. Hydrothermal reduction route to $\mathrm{Mn}(\mathrm{OH})_{2}$ and $\mathrm{MnCO}_{3}$ nanocrystals. Mat. Chem. Phys. 2003, 82, 419-422.

81. Chen, X.; Wang, F.; Xu, J. Preparation of $\mathrm{VO}_{2}(\mathrm{~B})$ nanoflake with glycerol as reductant agent and its catalytic application in the aerobic oxidation of benzene to phenol. Top. Catal. 2011, 54, 1016-1023.

82. Kou, J.; Varma, R.S. Speedy fabrication of diameter-controlled Ag nanowires using glycerol under microwave irradiation conditions. Chem. Commun. 2013, 49, 692-694.

(C) 2013 by the authors; licensee MDPI, Basel, Switzerland. This article is an open access article distributed under the terms and conditions of the Creative Commons Attribution license (http://creativecommons.org/licenses/by/3.0/). 